\title{
Predicting the consequences of species loss using size-structured biodiversity approaches
}

\author{
Ulrich Brose $^{1,2, *}$, Julia L. Blanchard ${ }^{3}$, Anna Eklöf ${ }^{4}$, Nuria Galiana ${ }^{5}$, Martin Hartvig ${ }^{6,7,8}$, \\ Myriam R. Hirt ${ }^{1,2}$, Gregor Kalinkat ${ }^{9,10}$, Marie C. Nordström ${ }^{11}$, Eoin J. O’Gorman ${ }^{12}$, \\ Björn C. Rall ${ }^{1,2}$, Florian D. Schneider ${ }^{13}$, Elisa Thébault ${ }^{14}$ and Ute Jacob ${ }^{15}$
}

${ }^{1}$ German Centre for Integrative Biodiversity Research (iDiv) Halle-Jena-Leipzig, 04103, Leipzig, Germany

${ }^{2}$ Faculty of Biology and Pharmacy, Institute of Ecology, Friedrich Schiller University Jena, 07743, Jena, Germany

${ }^{3}$ Institute for Marine and Antarctic Studies and Centre for Marine Socioecology, University of Tasmania, 20 Castray Esplanade, Battery Point TAS 7004, Australia

${ }^{4}$ Theoretical Biology, Department of Physics, Chemistry and Biology, Linköping University, SE-581 83, Linköping, Sweden

${ }^{5}$ Ecological Networks and Global Change Group, Experimental Ecology Station, Centre National de la Recherche Scientifique, 09200, Moulis, France

${ }^{6}$ Center for Macroecology, Evolution and Climate, Natural History Museum of Denmark, University of Copenhagen, DK-2100, Copenhagen, Denmark

${ }^{7}$ National Institute of Aquatic Resources, Technical University of Denmark, DK-2920, Charlottenlund, Denmark

${ }^{8}$ Systemic Conservation Biology Group, J.F. Blumenbach Institute of Zoology and Anthropology, Georg-August University of Göttingen, 37073 , Göttingen, Germany

${ }^{9}$ Department of Biology and Ecology of Fishes, Leibniz-Institute of Freshwater Ecology and Inland Fisheries, 12587, Berlin, Germany

${ }^{10}$ Department of Fish Ecology and Evolution, Eawag, 6047, Kastanienbaum, Switzerland

${ }^{11}$ Environmental and Marine Biology, Abo Akademi University, FI-20520, Abo, Finland

${ }^{12}$ Imperial College London, Silwood Park Campus, Buckhurst Road, Ascot, Berkshire, SL5 7PY, UK

${ }^{13}$ Institut des Sciences de l'Evolution, Université Montpellier, CNRS, IRD, EPHE, CC065, 34095, Montpellier Cedex 05, France

${ }^{14}$ Institute of Ecology and Environmental Sciences - Paris, UMR 7618 (UPMC, CNRS, IRD, INRA, UPEC, Paris Diderot), Université Pierre et Marie Curie, 75005, Paris, France

${ }^{15}$ Department of Biology, Institute for Hydrobiology and Fisheries Science, Center for Earth System Research and Sustainability (CEN),

KlimaCampus, University of Hamburg, 22767, Hamburg, Germany

\begin{abstract}
Understanding the consequences of species loss in complex ecological communities is one of the great challenges in current biodiversity research. For a long time, this topic has been addressed by traditional biodiversity experiments. Most of these approaches treat species as trait-free, taxonomic units characterizing communities only by species number without accounting for species traits. However, extinctions do not occur at random as there is a clear correlation between extinction risk and species traits. In this review, we assume that large species will be most threatened by extinction and use novel allometric and size-spectrum concepts that include body mass as a primary species trait at the levels of populations and individuals, respectively, to re-assess three classic debates on the relationships between biodiversity and (i) food-web structural complexity, (ii) community dynamic stability, and (iii) ecosystem functioning. Contrasting current expectations, size-structured approaches suggest that the loss of large species, that typically exploit most resource species, may lead to future food webs that are less interwoven and more structured by chains of interactions and compartments. The disruption of natural body-mass distributions maintaining food-web stability may trigger avalanches of secondary extinctions and strong trophic cascades with expected knock-on effects on the functionality of the ecosystems. Therefore, we argue that it is crucial to take into account body size as a species trait when analysing the consequences of biodiversity loss for natural ecosystems. Applying size-structured approaches provides an integrative ecological concept that enables a better understanding of each species' unique role across communities and the causes and consequences of biodiversity loss.
\end{abstract}

\footnotetext{
*Address for correspondence (Tel.: +49 (0) 34197 33205; E-mail: ulrich.brose@idiv.de; ubrose@gwdg.de).
} 
Key words: biodiversity, extinctions, complexity, food webs, stability, ecosystem functioning, global change, allometric scaling, size spectrum.

\section{CONTENTS}

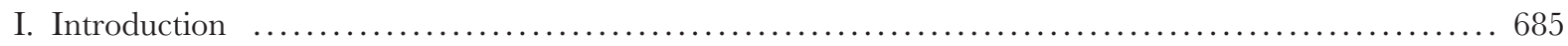

(1) Extinctions, traditional biodiversity sciences and open questions $\ldots \ldots \ldots \ldots \ldots \ldots \ldots \ldots \ldots \ldots \ldots 6 . \ldots \ldots \ldots$

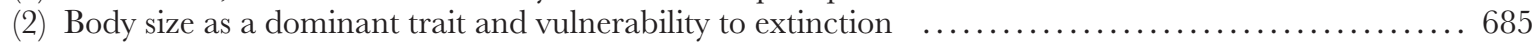

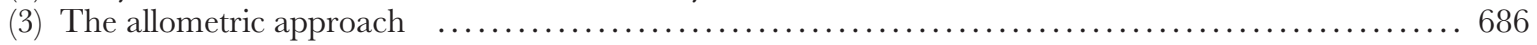

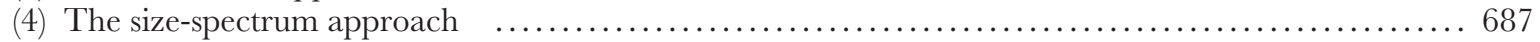

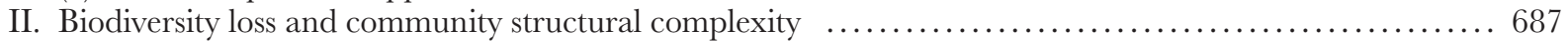

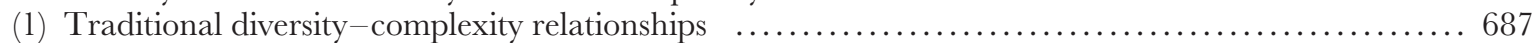

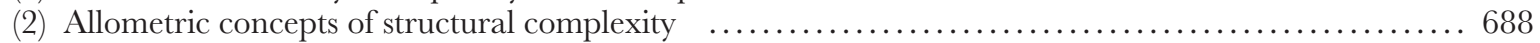

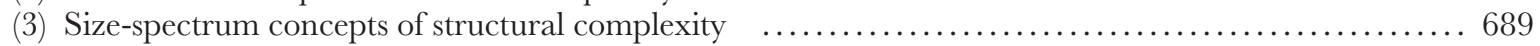

(4) Summary: consequences of non-random species loss for structural complexity $\ldots \ldots \ldots \ldots \ldots \ldots \ldots 689$

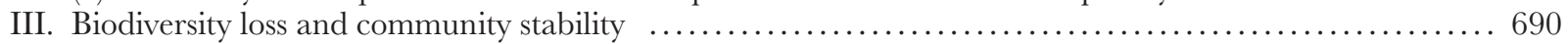

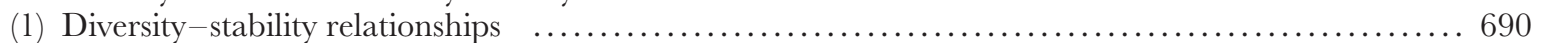

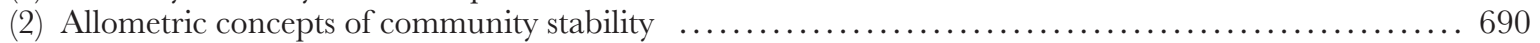

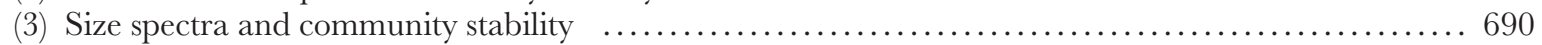

(4) Summary: consequences of non-random species loss for community stability $\ldots \ldots \ldots \ldots \ldots \ldots \ldots 691$

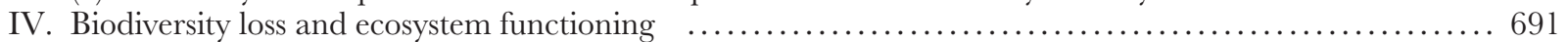

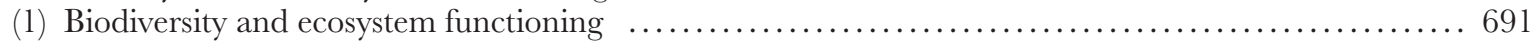

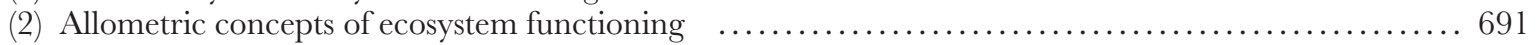

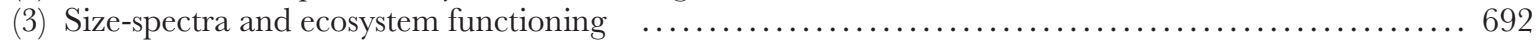

(4) Summary: consequences of non-random species loss for ecosystem functioning $\ldots \ldots \ldots \ldots \ldots \ldots \ldots 63$

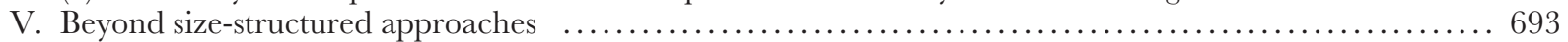

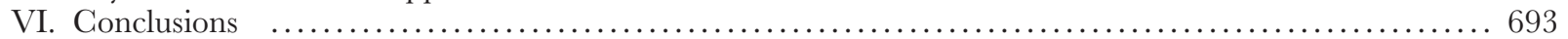

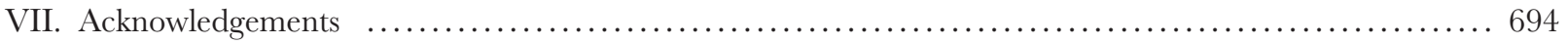

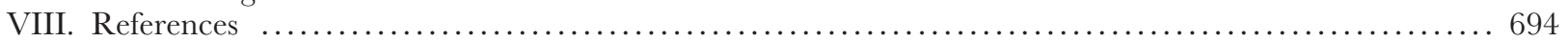

\section{INTRODUCTION}

\section{(1) Extinctions, traditional biodiversity sciences and open questions}

The world's ecosystems are currently exposed to species extinctions at a higher rate than ever before (Barnosky etal., 2011) leading to projected strong decreases in their biodiversity (Pereira et al., 2010). This biodiversity crisis has motivated intensive debates about how biodiversity losses will affect natural species communities concerning their food-web structure (often referred to as complexity), dynamic stability, ecosystem functioning and the subsequent provisioning of ecosystem services. Traditionally, these questions have been tackled by detailed descriptions of specific communities that assign each species its taxonomic Latin binomial. Subsequently, the functional role (for example, trophic level in Fig. 1) is described individually for each species in the community (Fig. 1A). This allows the creation of interaction networks (networks connecting species by their interactions such as feeding), in which the species have defined positions (Fig. 1B). However, neither the taxonomic identity of the species nor its trophic level predicts any specific links among species thus yielding random networks (Fig. 1B). Hence, these traditional biodiversity approaches assess community differences by species richness and predict the consequences of species loss by averaging across species without accounting for their traits. We can illustrate this point by an example of the functional consequences of losing 5 species from a community of 40 species. Under the assumption of random species loss and without knowledge of species traits, predictions equal the average across all combinations of five species that could potentially be lost. Such simplified traditional biodiversity research has identified important natural and anthropogenic effects on biodiversity, but has hampered a mechanistic understanding of the consequences of biodiversity loss across ecosystems by ignoring species' traits.

\section{(2) Body size as a dominant trait and vulnerability to extinction}

This line of research has led to the conclusion that one of the key challenges in biodiversity research is how to include general species traits in biodiversity models and concepts. In this vein, recent biodiversity theory has started to include body size as a dominant species trait to predict the number of species in phylogenetic groups or along global gradients (Gillooly \& Allen, 2007; Reuman etal., 2014). These results suggest that the consequences of extinctions may also depend on the size of the species that are lost. The current changes in biodiversity by species extinctions often stem from anthropogenic activities such as overharvesting, destruction of habitats and pollution (Purvis etal., 2000), 
(A)

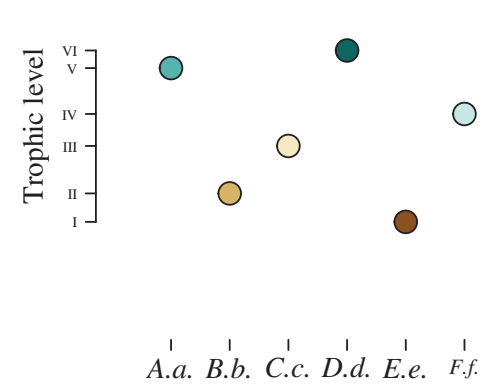

Taxon name

(B)

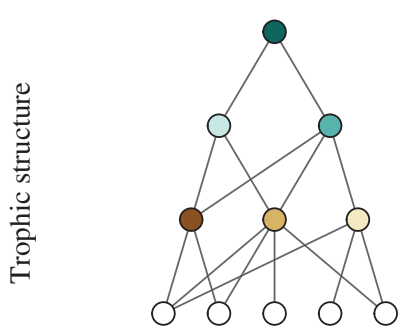

(C)

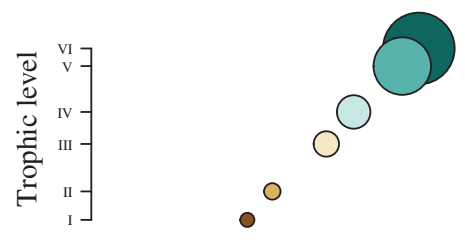

(E)

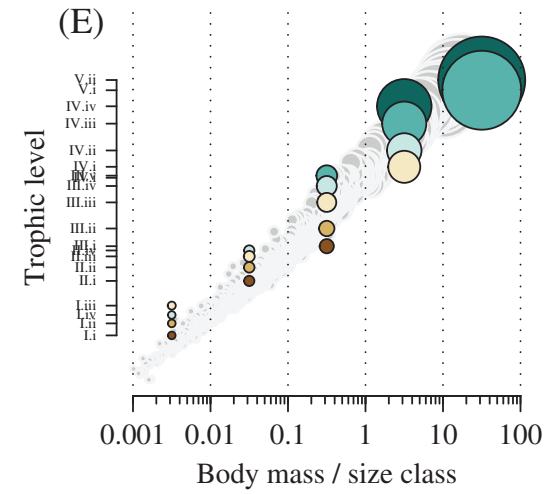

(F)
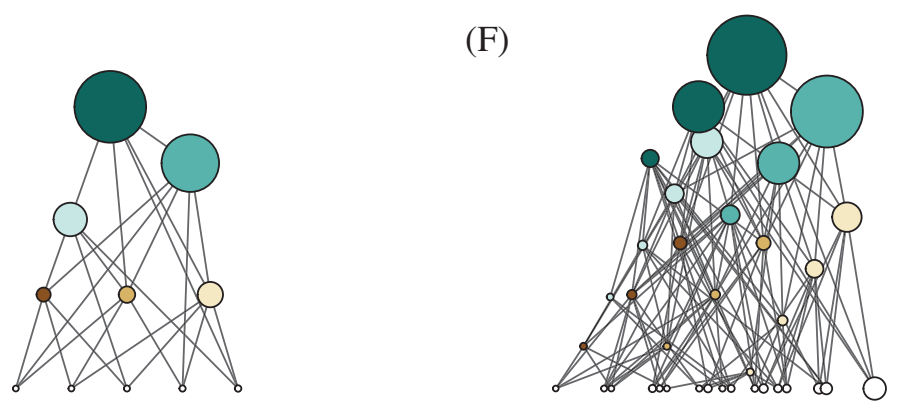

Fig. 1. Three approaches to ecological community description. Latin numbers are used for functional traits, e.g. trophic levels. (A) The taxonomic approach categorizes trophic levels of species according to taxonomy (unique colour code), yielding (B) networks of species (nodes) and their interactions (links between nodes) with randomly distributed trophic levels. (G) The allometric approach orders species according to their body mass based on allometric (often power-law) scaling, creating (D) interaction networks exhibiting increasing body masses (and scaling of associated traits) with trophic levels. (E) The size-spectrum approach either lumps all individuals across species in distinct size bins (community-level size spectra, grey dots) or separates species according to taxonomy and size class (species-level size spectra, coloured dots), resulting in (F) networks with species occupying different trophic levels across size classes. Note that all panels have the same number of (coloured) non-basal species.

and species' abilities to cope with these threats are in turn dictated by their biological traits. Certain key traits are likely to influence extinction vulnerability: in particular high trophic level, large home ranges, slow reproduction rates and low population density have been identified to increase the probability of extinction (Gaston \& Blackburn, 1995; McKinney, 1997; Purvis et al., 2000; Cardillo, 2003; Cardillo etal., 2005; Olden, Hogan \& Vander Zanden, 2007; Davidson etal., 2009; Binzer etal., 2011; Lee \& Jetz, 2011). Most of these traits are strongly correlated with body size: species with a large body size are often positioned at high trophic levels, require large home ranges, have slow reproduction rates, and are found at lower densities (Brown et al., 2004; White et al., 2007; Riede et al., 2011 b; Tamburello, Côté \& Dulvy, 2015). Despite interesting exceptions such as habitat specialists or species with extreme sensitivity to environmental pollutants, a majority of recent findings illustrate that biodiversity loss should be a non-random process during which extinction likelihood increases with body size (Johnson, 2002; Cardillo et al., 2005; Olden et al., 2007; Gill et al., 2009; Rule et al., 2012; Sallan \& Galimberti, 2015). Accordingly, the current extinction wave may cause a deconstruction of natural communities (de Ruiter etal., 2005) removing species sequentially from the largest to the smallest. The ideas and concepts of this review are based on this assumption that extinction risk increases with body size. We explore the consequences of biodiversity loss under two different concepts that include body size as a dominant species trait (hereafter: size-structured concepts): the allometric (using average body masses at the species level) and the size-spectrum approach (using body masses at the level of individuals). These two size-structured approaches as well as the traditional, taxonomic approach generate different network structures of communities (Fig. 1) and make diverging predictions of the consequences of species extinctions.

\section{(3) The allometric approach}

The allometric approach applies scaling relationships between species traits such as metabolic or growth rates and their average body mass (Peters, 1983; Brown etal., 2004; Brose, 2010). To balance the metabolic energy requirements, the overall feeding rates (across all interactions) of many organisms also follow similar allometric scaling relationships (e.g. Wahlström et al., 2000; Aljetlawi, Sparrevik \& Leonardsson, 2004; Brose etal., 2008; Rall etal., 2012). These energetic constraints mean that the average body sizes of species also determine their feeding links (who consumes 
whom) in natural food webs (Warren et al., 2005; Woodward etal., 2005; Petchey etal., 2008; Arim etal., 2010; Eklöf etal., 2013) and the strengths of their pairwise interactions describe how much is consumed through specific interactions (Emmerson \& Raffaelli, 2004; Brose et al., 2008; Kalinkat et al., 2013). Across ecosystem types, increasing average body sizes of species are thus correlated with their functional roles such as trophic levels (Riede etal., 2011b; Fig. 1C) and the number of links to consumers and resources (Otto, Rall \& Brose, 2007; Digel, Riede \& Brose, 2011; Thierry et al., 2011b). Additionally, optimal foraging models can use consumer and resource body masses to predict specific links among species (Petchey et al., 2008, 2011). Based on these principles, the allometric approach uses species-averaged body masses to predict not only trophic levels (Fig. 1G) but also specific interactions among species composing the network structure of the communities (Fig. 1D) and the strength of each of these interactions. Here, we will focus on population-level interaction strengths that multiply per capita interaction strengths of average individuals with population abundance (see Berlow et al., 2009 for details). We illustrate how this allometric concept can predict the consequences of species loss by employing species-averaged body masses as a dominant trait.

\section{(4) The size-spectrum approach}

The size-spectrum approach, which has mainly been employed in marine ecology, is based on the notion that body size is an individual property and not a property of a species. This is due to the fact that species grow across several size classes from offspring to adult size and therefore individuals may experience transitions between markedly different trophic levels over their ontogenetic development (Werner \& Gilliam, 1984; Pimm \& Rice, 1987; Davis etal., 2011; Rudolf \& Rasmussen, 2013). For these organisms, it may be inappropriate to ascribe a body size to the species as it is the size of the individual that determines characteristics such as metabolic rate and predator-prey relationships. Hence, in the community size-spectrum approach, individuals are grouped into size classes independent of their taxonomic identity (Sheldon \& Parsons, 1967; Andersen \& Beyer, 2006; Reuman etal., 2008; shown as grey dots for individuals in Fig. 1E). More recently, species-level size-spectrum approaches have started to analyse the distribution of traits such as trophic levels across size classes for taxonomically defined species independently (Boudreau \& Dickie, 1989; Andersen \& Beyer, 2006; Hartvig, Andersen \& Beyer, 2011). The growth of species through several size classes causes ontogenetic niche shifts in diet breadth and trophic levels (de Roos \& Persson, 2001, 2013; Rudolf \& Rasmussen, 2013; Hartvig \& Andersen, 2013; see Fig. 1E, coloured dots indicating that species occur in several size classes). In consequence, this yields interaction networks in which species occur several times at different trophic levels according to their size classes (Fig. 1F). This implies that the consequences of species loss can be predicted by knowledge of the size classes of the ontogenetic stages of the species.
Below, we review the three major debates addressing the consequences of biodiversity loss for the structure (Section II), stability (Section III) and functioning (Section IV) of natural communities. We add a novel aspect to these debates by comparing predictions of taxonomic, allometric and size-spectrum concepts. Synthesizing these concepts highlights novel research agendas at their intersections.

\section{BIODIVERSITY LOSS AND COMMUNITY STRUCTURAL COMPLEXITY}

\section{(1) Traditional diversity-complexity relationships}

The structural complexity of ecological communities is often described by two main parameters: the number of species and the number of trophic (i.e. feeding) interactions. Here, we refer to the number of species as biodiversity and to the number of feeding interactions as the complexity of the community. The key role of trophic interactions as one of the central organizing concepts in community ecology explains the continuous interest in topological community descriptions among ecologists. Pioneering food-web studies described how trophic links among species compose complex networks (Cohen, 1978; Pimm, 1982). Since then, many network variables have been proposed based on the number of nodes and the number of links between them to allow for ecologically meaningful comparisons among different food webs across a variety of systems (Martinez, 1991; Dunne, 2005; Riede etal., 2010; Thompson etal., 2012). While classic studies assumed that linkage density (i.e. the number of links per species; Cohen \& Briand, 1984) or connectance (i.e. the proportion of possible links realized; Martinez, 1992) should be constant, recent comparisons, using more detailed data on food webs, suggested that both complexity parameters vary with diversity (Schmid-Araya et al., 2002; Riede et al., 2010). More specifically, communities of lower diversity are characterized by lower linkage density but higher connectance (Schmid-Araya et al., 2002; Riede etal., 2010). This apparent paradox finds its explanation in a power-law increase in the number of links with diversity exhibiting an empirical exponent higher than one (implying that the number of links per species increases with increasing diversity) but lower than two (yielding decreases in connectance with increasing diversity; for details see Riede et al., 2010). In consequence, this suggests that species loss (illustrated by the randomly chosen red node in Fig. 2A) is associated with the loss of links (red links in Fig. 2B), with the remaining species (non-red nodes in Fig. 2A) having on average fewer links to other species while the food web should have a higher connectance (Fig. 2B). However, these studies compare empirical food webs of different species richness and their predictions are based on averages across all species and do not account for unequal extinction probabilities. Hence, these predictions are unlikely to hold for the deconstruction of complexity following real species losses. 
(A)

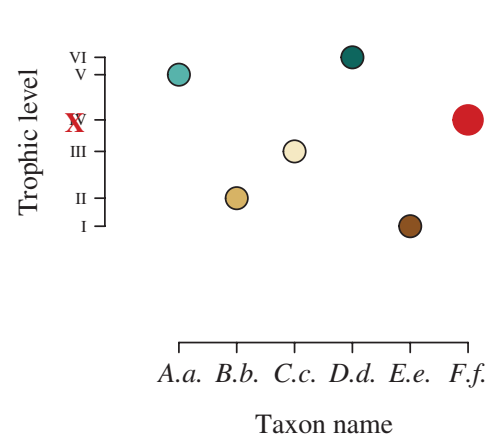

(B)

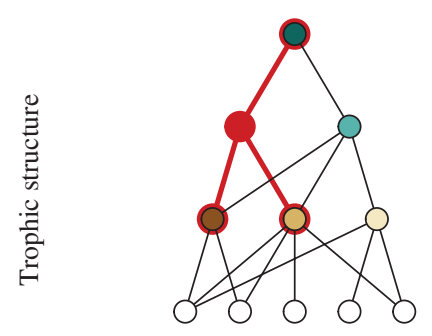

(C)
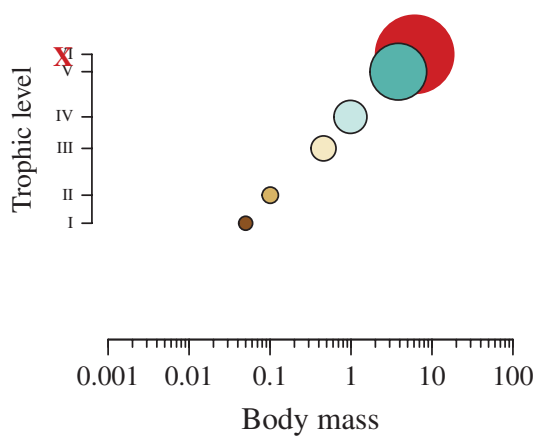

(D)

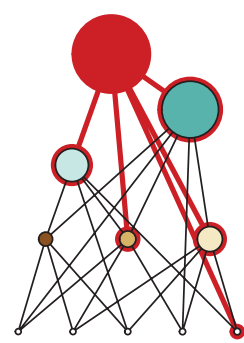

(E)

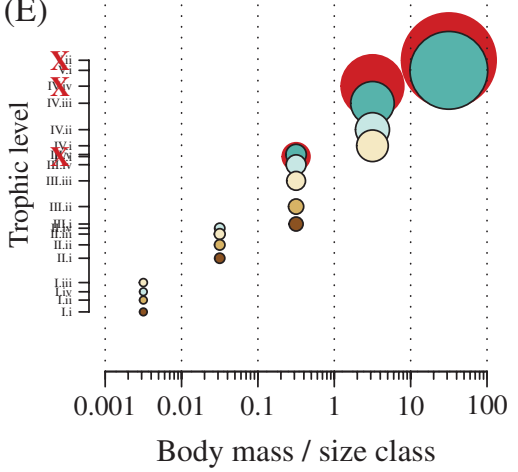

(F)

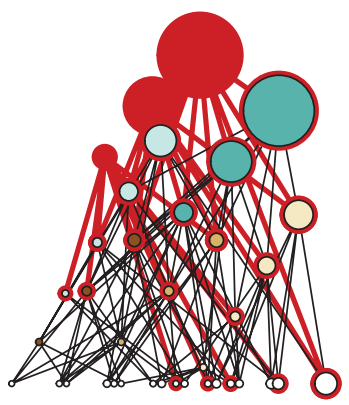

Fig. 2. Effects of species loss on structural complexity and community stability. Species loss (red node) causes loss of links (red links) to other species, which changes the complexity (number of links and connection probability) of the networks. A number of species is affected indirectly (nodes with red circles), which can lead to their dynamic instability and secondary extinction. These effects differ under the taxonomic approach $(\mathrm{A}, \mathrm{B})$, the allometric approach $(\mathrm{C}, \mathrm{D})$ and the size-spectrum approach $(\mathrm{E}, \mathrm{F})$. The species removed is randomly chosen under the taxonomic approach $(\mathrm{A})$, the largest species under the allometric approach $(\mathrm{C})$, and the species with the largest adults (all juvenile nodes are also removed) under the size-spectrum approach (E).

\section{(2) Allometric concepts of structural complexity}

Trophic interactions are to a large extent dictated by species traits. Pioneering studies documented the explicit importance of species body masses for the formation of predator-prey interactions in food webs (Warren \& Lawton, 1987; Cohen et al., 1993). Subsequently, these patterns were generalized across ecosystems and different species groups to show that (i) predator and prey masses are systematically correlated (Brose et al., 2006a; Barnes etal., 2010; Riede etal., 2011b), (ii) predator body masses increase with trophic level, and (iii) the ratio between predator and prey body masses decreases with trophic level with specific slopes for each ecosystem type (Riede etal., 2011b). Together, these findings suggest that consumers become progressively larger from the base to the top of food webs but more similarly sized to their prey (as indicated by the increasing size of the nodes in Fig. 2B). Thus, the loss of large top predators should decrease the average body masses of the species in the food web, but surprisingly it should also increase the average predator-prey body-mass ratios. This would yield communities of smaller species that have a higher size difference to their prey.

Moreover, the number of interactions a species possesses tends to vary with body size. This linkage density of a species can be described using different measurements: generality describes the number of ingoing links to prey species, vulnerability describes the number of outgoing links to consumer species, and degree (linkedness) describes the sum of all ingoing and outgoing links (Dunne, 2005). Allometric degree distributions describe how these measurements of linkage density (generality, vulnerability and degree) scale with species body mass, irrespective of taxonomy or other traits (Otto et al., 2007). Analyses of a large number of empirical food webs revealed increasing generality and decreasing vulnerability with the average body mass of a species as a general pattern (Otto et al., 2007; Digel et al., 2011; Thierry et al., 2011 b; Yvon-Durocher et al., 2011c). These patterns find their explanation in several potential mechanisms, including (i) that the number of (smaller) resources available increases with consumer body mass, (ii) an increasing fundamental, physiological generality of larger consumers, and (iii) the larger space that large consumers sample for resources. These allometric degree distributions imply that natural food webs possess a specific architecture: large top predators have a wide prey spectrum and small basal species have a wide consumer spectrum. Despite some exceptions (e.g. specialized parasitic top predators), this body-mass signature seems to be consistent across both different ecosystem types and organism groups (Riede et al., 2011b) although predator-prey body-size relationships also depend on feeding behaviour (Klecka \& Boukal, 2013) and on predator and prey phylogeny (Naisbit et al., 2011). These empirical patterns across communities suggest that the loss of the largest species with the highest linkage density (red node in Fig. 2C) should result in a decrease 
of food-web complexity (red links in Fig. 2D). Additionally, these large top predators usually distribute their trophic links across prey of different trophic levels (Fig. 2D, red links) thus creating a web-like network structure with short pathways between different populations. In consequence, after the loss of these highly linked top predators, future food webs should be less interwoven by links across trophic levels, more structured by chains of interactions and compartments, and generally have lower trophic levels (Fig. 2C, D).

Not only the number but also the identities of feeding interactions are strongly dependent on species body masses (Rohr et al., 2010; Eklöf et al., 2013). Understanding the role of body-mass distributions in defining species interactions can therefore give us valuable insights into the organization of ecological networks (Stouffer, Rezende \& Amaral, 2011). A community-wide structural measurement that has gained much interest in food-web research is intervality, expressing that all species can be ordered in such a way that all consumers feed on a non-interrupted interval of prey species (the interval does not include any prey that is not consumed). This characteristic has been employed as a central rule in commonly used models for food-web structure (Cohen \& Briand, 1984; Williams \& Martinez, 2000). While subsequent models dropped this assumption (Cattin et al., 2004; Allesina, Alonso \& Pascual, 2008), empirical analyses showed that natural food webs are close to (but not fully) interval (Stouffer, Camacho \& Amaral, 2006) and identified body size as an important factor underlying this intervality (Warren \& Lawton, 1987; Cohen, Jonsson \& Carpenter, 2003; Stouffer et al., 2011; Zook et al., 2011). Consistent with these empirical patterns, laboratory experiments documented that predators feed within size ranges of potential prey that are limited by decreasing success rates towards smaller prey (lower chances of catching prey) and larger prey (lower chances of subduing prey; Brose et al., 2008; Brose, 2010). Consequently, rigorous empirical tests documented that consumer and resource body size are often the most important, although not the only, species-specific traits explaining the largest proportion of trophic linkages among species (Rohr et al., 2010; Williams, Anandanadesan \& Purves, 2010; Eklöf et al., 2012, 2013). Some recent approaches used the systematic relationships between consumer and resource body masses and optimal foraging theory to develop mechanistic models predicting the trophic links among species (Petchey etal., 2008, 2011; Allesina, 2011). These trait-based models can predict the food-web linkages among populations following the loss of specific species such as large top predators (Thierry etal., 2011a). One advantage over prior static food-web models is that they can account for the re-wiring of trophic links when consumers switch to new resources after losing others. While some studies addressed the risk of secondary extinctions (Curtsdotter etal., 2011; Riede etal., 2011a; Thierry etal., 2011a), the structural consequences of species loss for natural communities remain to be explored. In future studies, the application of allometric and other trait-based food-web models (Petchey et al., 2008, 201 1; Allesina, 2011) to scenarios of species extinctions offers a generalized and mechanistic understanding of how they will affect interaction structure among the species.

\section{(3) Size-spectrum concepts of structural complexity}

As discussed above, recent explorations of food-web intervality have shown that consumers in natural communities feed within specific ranges of prey body masses, which predicts the links among species depending on their body masses. Yet, the range of intraspecific variation in body size for many species may muddy the waters. An analysis of highly resolved food webs showed that species-based analysis of interactions may obscure patterns that only emerge when within-species individual body sizes are employed (Gilljam et al., 2011). Additionally, relationships between predator body mass and (i) prey body mass, and (ii) predator-prey mass ratio were more accurately represented when analysing interactions between individuals instead of species with averaged body sizes (Gilljam et al., 2011). Adopting an individual-based approach may thus improve the predictability of empirically observed community structures. This research agenda is realized by species-level size-spectrum approaches that simultaneously group individuals into species and size classes (Hartvig et al., 2011). The topology is more complex compared to classical food webs of unstructured populations as the size classes of a species possess independent sets of links that change during ontogenetic growth (see the three size classes of the red species in Fig. 2E). Accordingly, the loss of species with the largest adult individuals will also lead to the loss of the juvenile nodes with smaller body sizes and lower trophic levels (Fig. 2E). Consequently, this causes losses of links across trophic levels with the most pronounced effect at the highest trophic levels where species are less redundant (Fig. 2F). While the predictions concerning the loss of trophic levels are less clear, species loss in size-spectrum models thus yields similar conclusions as the allometric models described above concerning the average linkage density of the species and the connectance of the food webs.

\section{(4) Summary: consequences of non-random species loss for structural complexity}

Traditional studies of changes in complexity with biodiversity employ data across communities that differ in these two characteristics and demonstrate power-law increases in connectance with decreasing species richness. This would imply that species loss should lead to communities with higher connectance in which species are more interwoven with each other by their trophic interactions. Accounting for the fact that species with large body masses are often most vulnerable to extinctions, allometric and size-spectrum concepts of biodiversity loss suggest different conclusions. Given that large species often feed on prey from a wide size range and thus have a higher number of interactions than small species, their loss should result in a decrease of food-web complexity and a dominance of simple chain-like link structures in food-web compartments. 


\section{BIODIVERSITY LOSS AND GOMMUNITY STABILITY}

\section{(1) Diversity-stability relationships}

Over several decades, the relationship between the diversity of food webs and their stability has been central to ecology (McCann, 2000; Montoya, Pimm \& Solé, 2006; Allesina \& Tang, 2012). Stability is higher for natural food webs than for random networks (Yodzis, 1981; Neutel, Heesterbeek \& de Ruiter, 2002; but see Allesina \& Tang, 2012), which was related to the fact that natural food webs possess a non-random structure in their topology (Williams \& Martinez, 2000) and non-random distributions of interaction strengths across species (de Ruiter, Neutel \& Moore, 1995). Overall, these studies documented some surprising regularities in the way food webs are structured across different ecosystem types, but the question of how they are constrained into those stable, non-random configurations remained unanswered. Concerning the risk of secondary extinctions as one measure of stability, species deletion studies unraveled that in particular the loss of the most connected species (i.e. those that have most interactions with other species) would severely undermine the structural integrity of the communities (Solé \& Montoya, 2001; Dunne, Williams \& Martinez, 2002). In these taxonomic food-web models, however, all species have equal or randomly assigned traits and the likelihood of extinction does not predictably differ among them. This suggests that effects of extinctions can potentially occur anywhere in the community while on average the indirect effects may often be restricted to a local sphere of a few species that are directly linked (species with red circles in Fig. 2B).

\section{(2) Allometric concepts of community stability}

By contrast, allometric concepts identified aspects of natural body-mass distributions such as the increase in body masses with trophic levels as the crucially important structures that maintain food-web stability (Brose, Williams \& Martinez, 2006b; Otto etal., 2007; Heckmann etal., 2012). These empirically supported increases in body masses with the trophic position of a species (Riede etal., 2011b) cause simultaneous decreases in the per unit biomass rates of respiration and consumption, which are responsible for the stabilizing effects of allometry (Kartascheff, Guill \& Drossel, 2009). Similarly, the distribution and correlation of interaction strengths emerging from size structure and allometric relations also favour stability (Tang, Pawar \& Allesina, 2014). These results may suggest that the loss of large-bodied species will most likely imply the most severe consequences for the stability of natural communities and also indirect effects on other species may be distributed across trophic levels (species with red circles in Fig. 2D). Dynamic food-web model studies demonstrated that the loss of basal species as well as the loss of large-bodied top species are most likely to trigger avalanches of secondary extinctions (Gurtsdotter et al., 2011; Riede et al., 2011a). While the consequences of basal loss find their explanation in the disruption of bottom-up energy supply chains in the food web (Curtsdotter et al., 2011), the severe consequences of top predator loss remained more opaque. Potential explanations include trophic cascades and the lower body masses of the new top predators that may induce more cyclic and unstable dynamics. However, these consequences need to be reconciled with the higher predator-prey body-mass ratios that result from top-predator loss (see Section II) that are expected to have a positive effect on community stability and extinction risks. Future research will thus need to disentangle these mechanistic consequences of top-predator loss to provide a general understanding of why and in which cases it causes avalanches of secondary extinctions.

\section{(3) Size spectra and community stability}

In community size-spectrum approaches, body-size-related traits have a dominant effect on stability: lower mean preferred predator-to-prey mass ratios, wider diet breadth of predators and higher growth conversion efficiency, and larger maturation size all result in higher stability in terms of faster recovery from perturbations (Blanchard et al., 2009; Law etal., 2009; Plank \& Law, 2012). The community size-spectrum is the sum of all species size-spectra, and as species of different asymptotic sizes have different life-history trade-offs, individuals of equal size across species may have different growth rates. Interestingly, the diversity in growth rates across the community size-spectrum at a given body size plays an important role in enhancing stability (Zhang et al., 2013). Similarly, it was shown that using just a single trait (e.g. size at maturation) to characterize functional species identity is insufficient for assembling species-rich food webs of size-structured populations (Hartvig \& Andersen, 2013). These results suggest that species traits that are not related to body size also have a strong effect on the stability of size-spectrum models. Future research thus needs to integrate these additional traits in community and species-level size-spectrum approaches addressing stability.

In species-level size spectra, species occur with their life stages in different size classes (Fig. 2E), which allows addressing questions on how removal of specific size classes affects communities. These approaches have demonstrated that even more subtle changes in the size structure of populations that do not include complete extinctions can have severe consequences for ecological communities. For instance, predatory species shape the size-spectra of their prey populations, and changes of predator size-spectra through disturbances such as fishing can render the predator incapable of controlling the prey size distribution. This may lock the system in a state where competition between prey and small predators drives the predator population to a low-density state or even extinction (Walters \& Kitchell, 2001; Persson et al., 2007; van Leeuwen, de Roos \& Persson, 2008). Moreover, disrupting the slope of size spectra (e.g. steepening due to more small and fewer large individuals, as demonstrated through overfishing or warming) can lead to a less stable system due to inefficient transfer of energy 
through the food web and a shift towards faster growth rates and an increase in abundance fluctuations of the overall community (Yvon-Durocher etal., 2011a; Blanchard etal., 2012). Interestingly, species that appear as generalists can be highly specialized in each of their life stages, which makes them highly sensitive to the loss of the stages' specific resources (Rudolf \& Lafferty, 2011). Such sequential specialism can render the consequences of extinctions more detrimental if size-structured populations are accounted for. Ultimately, the loss of large-bodied individuals will reduce the maximum size of the size spectrum and likely trigger avalanches of secondary extinctions. The indirect effects through the life stages in smaller size classes of these species will distribute the perturbation across the entire networks (species with red circles in Fig. 2F).

\section{(4) Summary: consequences of non-random species loss for community stability}

Traditional studies have outlined the importance of natural food-web structures and distributions of interaction strengths across the links of these networks for maintaining the stability of natural ecosystems. Allometric approaches have shown that the increase in body mass with trophic level found in nature provides these critically important characteristics of natural communities. Extinctions of the large top predators will yield lower average body masses of the species but higher average predator-prey body mass ratios. As allometric approaches have shown that the former destabilizes and the latter stabilizes communities, future research will need to reconcile these two mechanistic consequences of extinctions. Size-spectrum approaches indicate that subtle changes in the size structure of populations preceding extinctions can have severe consequences for the stability of ecological communities. In conclusion, the consequences of anthropogenic stressors on top-predator populations may be more severe than previously expected, and future research will need to address whether they generally cause subtle changes of the size structure with strong consequences for community stability.

\section{BIODIVERSITY LOSS AND EGOSYSTEM FUNGTIONING}

\section{(1) Biodiversity and ecosystem functioning}

The relationship between biodiversity and ecosystem functioning has been addressed by numerous experimental studies (Tilman, 1999; Loreau \& Hector, 2001; see Balvanera et al., 2006, and Cardinale et al., 2006, for an overview). While decreases in species richness are usually associated with lower ecosystem functions such as primary productivity, litter decomposition and nutrient recycling, these relationships are most often better explained by the diversity of species functional traits (Cadotte et al., 2009; Flynn et al., 2011), and they are not necessarily simple and linear (Reiss et al., 2009). Compared to work on isolated trophic levels, assessments of changing biodiversity within a food-web context reveal a greater variability in the effects of species loss, as these are mediated by trophic interactions (Thébault \& Loreau, 2003; Duffy et al., 2007). Furthermore, species loss was often treated as random, i.e. focus was on reduced biodiversity per se rather than the identity or traits of the species going extinct. Hence, the effects of species loss on ecosystem functions can potentially emerge at different levels of the food webs, but there is a high likelihood that redundancy of species of the same trophic level or functional group can compensate for this loss (Fig. 3A). In naturally complex communities the diversity-functioning relationships thus often appear idiosyncratic (Emmerson etal., 2001; Harvey etal., 2013), which complicates predictions on the consequences of biodiversity loss. Hence, there is increasing recognition that simple inventories of species richness are not sufficient to predict consequences of species loss, because species differ in traits such as body size and communities differ in their structure.

\section{(2) Allometric concepts of ecosystem functioning}

In communities organized in multiple trophic levels, the functional consequences of losing a particular species

\section{(A) Taxonomic approach}

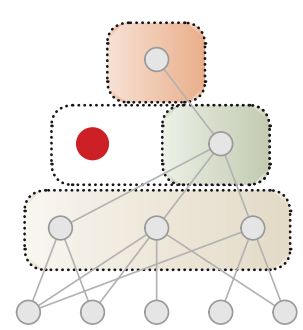

(B) Allometric approach

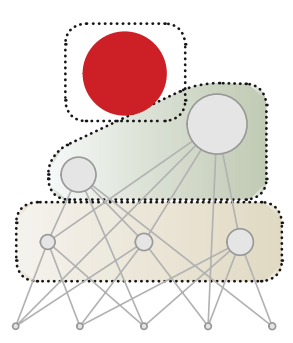

(C) Size-spectrum approach

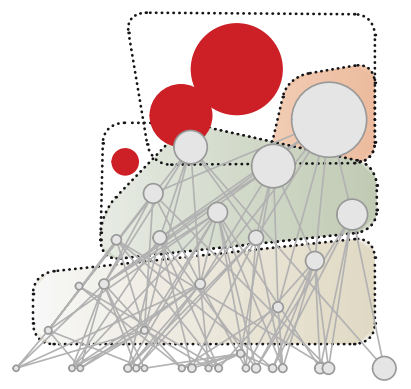

Fig. 3. Changes to ecosystem functioning following species loss. Species loss (red node, same rules of choice as in Fig. 2) eliminates its contribution to an ecosystem function (e.g. primary or secondary production, predation). The boxes indicate ecosystem functions carried out by specific trophic levels. Ecosystem functions after extinctions (coloured boxes) are thus lower than those in the intact community (dashed lines around boxes). The expected losses of ecosystem functions differ among the taxonomic (A), allometric (B) and size-spectrum $(\mathrm{G})$ approach. 
depend strongly on network structure and species traits such as body size (Solan etal., 2004; Dangles, Carpio \& Woodward, 2012; Schneider, Scheu \& Brose, 2012; Poisot, Mouquet \& Gravel, 2013). Even in communities exhibiting strong average increases in ecosystem functions with species diversity, the loss of a species from the full community can have positive, negative or neutral effects on this function depending on the community context (Schneider \& Brose, 2013). In multi-trophic predator communities with a clear size structure, large predators have their strongest interactions with other predators in intraguild links, whereas smaller predators mainly impose top-down control on basal primary producers or decomposers (Schneider et al., 2012). These systematic relationships allow understanding and prediction of the differences between the loss of large-bodied and small-bodied predators. For example, in three trophic level systems, the loss of large species should often cause decreases in the functions maintained by basal species (that are now exposed to stronger top-down control by the smaller intraguild predators), while the opposite should follow the loss of small predators (Schneider etal., 2012). Similarly, the loss of the largest top predator in four trophic level systems can release smaller intermediate predators, suppressing primary consumers and leading to an increase in functions carried out at the bottom of the web. As this concept was largely developed and tested by employing food-web motifs of few species, empirical studies scaling up these findings to more complex and more diverse communities are needed. Several studies have also started to integrate the effects of body size allometries into biodiversity - ecosystem functioning experiments (Ruesink \& Srivastava, 2001; McKie etal., 2008; Séguin et al., 2014). In particular, studies addressing effects of varying body-size distributions across populations on ecosystem functions provide important general knowledge (Yvon-Durocher \& Allen, 2012). Empirically, anthropogenic stressors such as land-use changes can shift the body-size distribution of the species communities, which reduces biodiversity and multiple ecosystem functions as well as the relationship between biodiversity and ecosystem functioning (Barnes et al., 2014). However, the reasons for this interplay between the body-size structure and the relationship between biodiversity and ecosystem functioning remain to be addressed. Modelling studies demonstrated that the loss of large species is expected to accelerate competitive exclusion among basal species (Brose, 2008) and trigger the strongest trophic cascades and indirect effects in natural ecosystems (Berlow et al., 2009), which may alter their functionality dramatically. Predicting the strength of these trophic cascades may also require accounting for the body-size structures of several trophic levels such as predators and herbivores separately (Séguin et al., 2014). While these indirect effects and trophic cascades are often hard to predict, allometric approaches predict a high likelihood of losing upper trophic levels where the redundancy of species is low (Fig. 3B). The strength and sign of the resulting trophic cascades, however, depends on community structures such as the number of trophic levels and the degree of connectance of the network. Future research needs to address the interplay of these parameters with trophic cascades to provide a more general and mechanistic understanding how the loss of large top predators may impair ecosystem functionality.

\section{(3) Size-spectra and ecosystem functioning}

Although extinctions and the resulting changes in the species composition of the community have not been a primary research topic of size-spectrum approaches, the distribution of the top predator life stages across trophic levels suggests that these effects may be less focused on upper trophic levels (red nodes in Fig. 3C). The effects of external stressors and disturbances on communities have been studied intensively, and it was shown that changes to community-level size spectra can have dramatic consequences for ecosystem functioning. For instance, warming is expected to alter the shape of size spectra, with steeper slopes (more small individuals, fewer large individuals) predicted from metabolic theory and temperature-size rules (Brown et al., 2004; Daufresne, Lengfellner \& Sommer, 2009). These effects have been demonstrated experimentally, with a shift towards smaller and more abundant phytoplankton in pond mesocosms (Yvon-Durocher etal., 2011a). The associated increase in gross primary productivity was not sufficient to offset the rise in ecosystem respiration and methane efflux, which have much higher activation energies, leading to a net input of $\mathrm{CO}_{2}$ and $\mathrm{CH}_{4}$ to the atmosphere (Yvon-Durocher et al., 2011 b).

Furthermore, many human pressures that are often thought to be acting at the species level may be more appropriately described as community-level actions that affect sub-populations of multiple species. For instance, fishing may be seen as a size-selective pressure on most fish species, which can trigger community-wide biomass changes through a trophic cascade to size ranges both larger and smaller than the targeted individuals (Andersen $\&$ Pedersen, 2010). Some survey data show that exploitation may change the overall slope of the community size-spectrum (Daan etal., 2005), although this is not always the case (Boldt et al., 2012). In consequence of these community-level changes, altered energy flow and biomass ratios at opposite ends of the size-spectrum following fishing activity may lead to similar changes in ecosystem functioning as those described for environmental stressors such as warming.

Predatory species shape the size-spectra of prey populations, and changes in predator size-spectra (e.g. through warming or fishing) can render the predator incapable of controlling the prey size distribution. Recent experimental manipulations of species-level size-spectra also suggest that loss of a species is not required to modify top-down control, with altered size structure of a predator population capable of causing trophic cascades affecting primary productivity (Jochum et al., 2012). Mechanistically, this is caused by the lower body masses of the predators that can provide a predation refuge for larger herbivores 
(Legagneux et al., 2014) with significant knock-on effects on primary production. Similarly, manipulating the life-stage structure of a keystone predator in pond communities altered its functional role, with concurrent changes in community structure, primary producer biomass, and ultimately net primary productivity and ecosystem respiration (Rudolf \& Rasmussen, 2013). Thus, the intraspecific size structure of natural populations and their modification by external stressors can be critically important for driving ecosystem functioning.

\section{(4) Summary: consequences of non-random species loss for ecosystem functioning}

Traditional studies of the consequences of extinctions in multitrophic communities experienced challenges by lacking predictions on species' extinction probabilities and idiosyncratic relationships with ecosystem functioning. Allometric approaches use the high likelihood of losing upper trophic levels to predict trophic cascades affecting lower trophic levels and ecosystem functions. However, the network structure of the community (e.g. the number of trophic levels and the connectance) can strongly modify the strength and sign of the resulting trophic cascades. In size-spectrum approaches, the differently sized life stages of the large top predators are distributed across trophic levels, which is likely to blur the pattern of trophic cascades. In addition, size-spectrum analyses have shown that even without losing species, small reductions in average body mass within a population such as those introduced by size-selective fishing can impose severe trophic cascades and alterations to ecosystem functioning (Jochum et al., 2012). However, a systematic exploration of how changes in the distribution of body masses across the species of a community as well as across the individuals of a species affect functioning at the community and ecosystem levels is still lacking. Future research needs to address how the targeted removal or loss of larger individuals alters mass-abundance scaling in the community with modifications of the ratio of autotrophic to heterotrophic biomass, and potential knock-on effects on gross primary production, ecosystem respiration, and carbon sequestration.

\section{BEYOND SIZE-STRUGTURED APPROAGHES}

In this review, our specific aim is to synthesize current knowledge on community-wide consequences of species loss. However, it is clear that body size is by no means the only species-specific trait determining the structure, stability and functioning of ecological communities. For instance, a recent study highlighted that even though body size is the most important predictor of network structure in many ecological networks, other traits can perform equally well or sometimes even better (Eklöf etal., 2013). The same study also showed that combining body size with other traits, e.g. habitat preference, significantly increased the proportion of the network structure that can be correctly predicted. Similarly, it is combinations of several traits that most accurately predict both species vulnerability to extinction (Davidson et al., 2009) as well as consequences of the loss. However, if the choice is restricted to one single trait, body size is usually the strongest candidate.

There are, nevertheless, ecological communities, or parts of ecological communities, where body size is potentially of inferior importance. For instance, in communities that do not follow the basic body-size structure discussed here such as food webs when parasites are included (Lafferty, Dobson \& Kuris, 2006; Lafferty et al., 2008) or when small insects feed on large plants. This also disconnects body size from some of the other traits predicting vulnerability to extinctions, such as high trophic level, since parasites and parasitoids in food webs are small-bodied but hold high trophic levels. It has been shown that including parasitic interactions in food webs modifies network structure (Dunne et al., 2013), but both the vulnerability and functional effects of the loss of parasites in ecological communities are poorly understood. It is, however, likely that due to their strong specialization, parasites and parasitoids will be equally vulnerable to extinction as their host species (Dunn etal., 2009). The loss of parasites may have strong effects on several ecosystem functions due to their pronounced role in regulating host species densities in communities (Poulin, 2011). There are also numerous types of non-trophic interactions that are of major importance for the structure and functioning of ecological communities, e.g. mutualistic, facilitative and competitive interactions (Kéfi et al., 2012). It will be a particularly interesting direction of future research to combine these non-trophic interactions with food webs composed of trophic interactions as the important energetic backbones of natural communities (Kéfi et al., 2015).

\section{GONGLUSIONS}

(1) Over several decades, biodiversity research has been dominated by important debates on how the loss of species from natural communities affects their structural complexity, dynamic stability and ecosystem functioning. While traditional studies employed taxonomic characterizations of species and often neglected their traits, novel size-structured approaches include body size as a supertrait, which allows predicting the consequences of non-random species loss assuming a positive correlation between extinction risk and body size.

(2) Concerning structural complexity, allometric and size-spectrum approaches both suggest that future food webs will be characterized by a higher number of links per species (on average each species has more interactions) but a lower connectance (on average species interact with a small fraction of the coexisting species). In addition, this is likely to yield interaction networks composed of simple food chains. In consequence, indirect effects of external stressors may travel more quickly through the networks of feeding interactions 
leading to a higher likelihood of trophic cascades in natural communities.

(3) Such changes in community structure are likely to cause severe knock-on effects on community stability. The loss of large-bodied species will simultaneously decrease the average body size of the species and increase the average predator-prey mass ratio. As these two changes may have contrary effects on food-web stability, the long-term consequences of species loss remain to be addressed. Furthermore, size-spectrum approaches have shown that even much more subtle reductions in the average body size of individuals within populations that do not include complete extinctions can yield strong trophic cascades that undermine dynamic stability and cause secondary extinctions.

(4) In consequence, allometric and size-spectrum approaches both suggest that species loss should have strong effects on ecosystem functions such as gross primary production, ecosystem respiration, and carbon sequestration. Both stronger indirect effects such as trophic cascades and changes in the stability of ecological communities are expected to reduce not only the average of many ecosystem functions but also their reliability by higher temporal variation.

(5) While these ecological advances by size-structured approaches provide an integrative ecological concept that enables a better understanding of each species' unique role across communities and the causes and consequences of biodiversity loss, our review has also identified important gaps in our knowledge. For instance, the consequences of shifting body-mass distributions across and within species for ecosystem functions and community stability need to be addressed in more detail. Integrating metabolic and food-web theory is essential to unravel the mechanistic pathways underlying how these body-mass distributions affect communities and ecosystems. Additionally, body size has a dominant effect on species' movement and the resulting spatial dynamics of ecological communities. Future studies need to address how extinctions of large species change these spatial dynamics and subsequently community structure, stability and functioning. Eventually, the integrated size-structured biodiversity research described herein will provide a mechanistic insight into the consequences of species loss.

\section{AGKNOWLEDGEMENTS}

This research was supported by a Research Network Programme of the European Science Foundation on body size and ecosystem dynamics (SIZEMIC). Funding has been provided to M.R.H., B.C.R. and U.B by the German Centre for integrative Biodiversity Research (iDiv) Halle-Jena-Leipzig funded by the German Research Foundation (FZT 118), to G.K. by the B-Types project funded through the Leibniz Competition (SAW-2013-IGB-2). M.H. acknowledges the Villum Foundation for postdoctoral support and the Danish
National Research Foundation for support to the Center for Macroecology, Evolution and Climate.

\section{REFERENGES}

Aljetlawi, A. A., Sparrevik, E. \& Leonardsson, K. (2004). Prey-predator size-dependent functional response: derivation and rescaling to the real world. Fournal of Animal Ecology 73, 239-252.

Allesina, S. (2011). Predicting trophic relations in ecological networks: a test of the allometric diet breadth model. Fournal of Theoretical Biology 279, 161-168.

Allesina, S., Alonso, D. \& Pascual, M. (2008). A general model for food web structure. Science 320, 658-661.

Allesina, S. \& TANG, S. (2012). Stability criteria for complex ecosystems. Nature 483, $205-208$.

Andersen, K. H. \& Beyer,J. E. (2006). Asymptotic size determines species abundance in the marine size spectrum. The American Naturalist 168, 54-61.

Andersen, K. H. \& Pedersen, M. (2010). Damped trophic cascades driven by fishing in model marine ecosystems. Proceedings of the Royal Society of London Series B: Biological Sciences 277, 795-802.

Arim, M., Abades, S. R., Laufer, G., Loureiro, M. \& Marquet, P. A. (2010). Food web structure and body size: trophic position and resource acquisition. Oikos 119, $147-153$

Balvanera, P., Pfisterer, A. B., Buchmann, N., He, J.-S., Nakashizuka, T., Raffaelli, D. \& Schmid, B. (2006). Quantifying the evidence for biodiversity effects on ecosystem functioning and services. Ecology Letters 9, 1146-1156.

Barnes, A. D., Jochum, M., Mumme, S., Haneda, N. F., Farajallah, A., Widarto, T. H. \& Brose, U. (2014). Consequences of tropical land use for multitrophic biodiversity and ecosystem functioning. Nature Communications 5, 5351.

Barnes, C., Maxwell, D., Reuman, D. C. \& Jennings, S. (2010). Global patterns in predator-prey size relationships reveal size dependency of trophic transfer efficiency. Ecology 91, 222-232.

Barnosky, A. D., Matzke, N., Tomiya, S., Wogan, G. O. U., Swartz, B., Quental, T. B., Marshall, G., McGuire, J. L., Lindsey, E. L., Maguire, K. C., Mersey, B. \& Ferrer, E. A. (2011). Has the Earth's sixth mass extinction already arrived? Nature 471, 51-57.

Berlow, E. L., Dunne, J. A., Martinez, N. D., Stark, P. B., Williams, R. J. \& Brose, U. (2009). Simple prediction of interaction strengths in complex food webs. Proceedings of the National Academy of Sciences of the United States of America 106, 187-191.

Binzer, A., Brose, U., Curtsdotter, A., Eklöf, A., Rall, B. C., Riede, J. O. \& de Castro, F. (2011). The susceptibility of species to extinctions in model communities. Basic and Applied Ecology 12, 590-599.

Blanchard, J. L., Jennings, S., Holmes, R., Harle, J., Merino, G., Allen, J. I., Holt, J., Dulvy, N. K. \& Barange, M. (2012). Potential consequences of climate change for primary production and fish production in large marine ecosystems. Philosophical Transactions of the Royal Society of London, Series B: Biological Sciences 367, 2979-2989

Blanchard, J. L., Jennings, S., Law, R., Castle, M. D., McCloghrie, P., Rochet, M.-J. \& Benoît, E. (2009). How does abundance scale with body size in coupled size-structured food webs? Fournal of Animal Ecology 78, 270-280.

Boldt, J. L., Bartkiw, S. C., Livingston, P. A., Hoff, G. R. \& Walters, G. E. (2012). Investigation of fishing and climate effects on the community size spectra of eastern Bering Sea fish. Transactions of the American Fisheries Society 141, 327-342.

Boudreau, P. R. \& Dickie, L. M. (1989). Biological model of fisheries production based on physiological and ecological scalings of body size. Canadian fournal of Fisheries and Aquatic Sciences 46, 614-623.

Brose, U. (2008). Complex food webs prevent competitive exclusion among producer species. Proceedings of the Royal Society of London Series B: Biological Sciences 275, $2507-2514$

Brose, U. (2010). Body-mass constraints on foraging behavior determine population and food-web dynamics. Functional Ecology 24, 28-34.

Brose, U., Ehnes, R. B., Rall, B. C., Vucic-Pestic, O., Berlow, E. L. \& Scheu, S. (2008). Foraging theory predicts predator-prey energy fluxes. Fournal of Animal Ecology 77, 1072-1078.

Brose, U., Jonsson, T., Berlow, E. L., Warren, P., Banasek-Richter, C., Bersier, L.-F., Blanchard, J. L., Brey, T., Carpenter, S. R., Cattin Blandenier, M.-F., Cushing, L., Dawah, H. A., Dell, T., Edwards, F., Harper-Smith, S., et al. (2006a). Consumer-resource body-size relationships in natural food webs. Ecology 87, 2411-2417.

Brose, U., Williams, R. J. \& Martinez, N. D. (2006b). Allometric scaling enhances stability in complex food webs. Ecology Letters 9, 1228-1236.

Brown, J. H., Gillooly, J. F., Allen, A. P., Savage, V. M. \& West, G. B. (2004). Toward a metabolic theory of ecology. Ecology 85, 1771-1789. 
Cadotte, M. W., Cavender-Bares, J., Tilman, D. \& Oakley, T. H. (2009). Using phylogenetic, functional and trait diversity to understand patterns of plant community productivity. PLoS One $\mathbf{4}$, e5695.

Cardillo, M. (2003). Biological determinants of extinction risk: why are smaller species less vulnerable? Animal Conservation 6, 63-69.

Cardillo, M., Mace, G. M., Jones, K. E., Bielby, J., Bininda-Emonds, O. R. P., Sechrest, W., Orme, C. D. L. \& Purvis, A. (2005). Multiple causes of high extinction risk in large mammal species. Science 309, 1239-1241.

Cardinale, B. J., Srivastava, D. S., Duffy, E. J., Wright, J. P., Downing, A. L., Sankaran, M. \& Jouseau, C. (2006). Effects of biodiversity on the functioning of trophic groups and ecosystems. Nature 443, 989-992.

Cattin, M. F., Bersier, L. F., Banasek-Richter, C., Baltensperger, R. \& Gabriel, J. P. (2004). Phylogenetic constraints and adaptation explain food-web structure. Nature 427, 835-839.

Cohen, J. E. (1978). Food Webs and Niche Space. Princeton University Press, Princeton.

Cohen, J. E. \& Briand, F. (1984). Trophic links of community food webs. Proceedings of the National Academy of Sciences of the United States of America 81, 4105-4109.

Cohen, J. E., Jonsson, T. \& Carpenter, S. R. (2003). Ecological community description using the food web, species abundance, and body size. Proceedings of the National Academy of Sciences of the United States of America 100, 1781-1786.

Cohen, J. E., Pimm, S. L., Yodzis, P. \& Saldana, J. (1993). Body sizes of animal predators and animal prey in food webs. Journal of Animal Ecology 62, 67-78.

Curtsdotter, A., Binzer, A., Brose, U., de Castro, F., Ebenman, B., Eklöf, A., Riede, J. O., Thierry, A. \& Rall, B. C. (2011). Robustness to secondary extinctions: comparing trait-based sequential deletions in static and dynamic food webs. Basic and Applied Ecology 12, 571-580.

Daan, N., Gislason, H., Pope, J. G. \& Rice, J. C. (2005). Changes in the North Sea fish community: evidence of indirect effects of fishing? ICES Journal of Marine Science: fournal du Conseil 62, 177-188.

Dangles, O., Carpio, C. \& Woodward, G. (2012). Size-dependent species removal impairs ecosystem functioning in a large-scale tropical field experiment. Ecology 93, $2615-2625$.

Daufresne, M., Lengfellner, K. \& Sommer, U. (2009). Global warming benefits the small in aquatic ecosystems. Proceedings of the National Academy of Sciences of the United States of America 106, 12788-12793.

Davidson, A. D., Hamilton, M. J., Boyer, A. G., Brown, J. H. \& Ceballos, G. (2009). Multiple ecological pathways to extinction in mammals. Proceedings of the National Academy of Sciences of the United States of America 106, 10702-10705.

Davis, A. M., Pearson, R. G., Pusey, B. J., Perna, C., Morgan, D. L. \& Burrows, D. (2011). Trophic ecology of northern Australia's terapontids: ontogenetic dietary shifts and feeding classification. Fournal of Fish Biology 78, 265-286.

Digel, C., Riede, J. O. \& Brose, U. (2011). Body sizes, cumulative and allometric degree distributions across natural food webs. Oikos 120, 503-509.

Duffy, J. E., Cardinale, B. J., France, K. E., McIntyre, P. B., Thebault, E. \& LOREAU, M. (2007). The functional role of biodiversity in ecosystems: incorporating trophic complexity. Ecology Letters 10, 522-538.

Dunn, R. R., Harris, N. C., Colwell, R. K., Koh, L. P. \& Sodhi, N. S. (2009). The sixth mass coextinction: are most endangered species parasites and mutualists? Proceedings of the Royal Society of London Series B: Biological Sciences 276, $3037-3045$.

Dunne, J. A. (2005). The network structure of food webs. In Ecological Networks: Linking Structure to Dynamics in Food Webs (eds M. Pascual and J. A. Dunne), pp. 27-86. Oxford University Press, New York.

Dunne, J. A., Lafferty, K. D., Dobson, A. P., Hechinger, R. F., Kuris, A. M., Martinez, N. D., Mclaughlin, J. P., Mouritsen, K. N., Poulin, R., Reise, K., Stouffer, D. B., Thieltges, D. W., Williams, R. J. \& Zander, C. D. (2013). Parasites affect food web structure primarily through increased diversity and complexity. PLoS Biology 11, e1001579.

Dunne, J. A., Williams, R. J. \& Martinez, N. D. (2002). Network structure and biodiversity loss in food webs: robustness increases with connectance. Ecology Letters 5, 558-567.

Eklöf, A., Helmus, M. R., Moore, M. \& Allesina, S. (2012). Relevance of evolutionary history for food web structure. Proceedings of the Royal Society of London Series B: Biological Sciences 279, 1588-1596.

Eklöf, A., Jacob, U., Kopp, J., Bosch, J., Castro-Urgal, R., Chacoff, N. P., Dalsgaard, B., de Sassi, C., Galetti, M., Guimarães, P. R., Lomáscolo, S. B., Martín González, A. M., Pizo, M. A., Rader, R., Rodrigo, A., Tylianakis, J. M., Vázquez, D. P. \& Allesina, S. (2013). The dimensionality of ecological networks. Ecology Letters 16, 577-583.

Emmerson, M. C. \& Raffaelli, D. (2004). Predator-prey body size, interaction strength and the stability of a real food web. Fournal of Animal Ecology 73, 399-409.

Emmerson, M. C., Solan, M., Emes, C., Paterson, D. M. \& Raffaelli, D. (2001). Consistent patterns and the idiosyncratic effects of biodiversity in marine ecosystems. Nature 411, 73-77.

Flynn, D. F. B., Mirotchnick, N., Jain, M., Palmer, M. I. \& NAEEM, S. (2011). Functional and phylogenetic diversity as predictors of biodiversity-ecosystem-function relationships. Ecology 92, 1573-1581.
Gaston, K. J. \& Blackburn, T. M. (1995). Birds, body size and the threat of extinction. Philosophical Transactions of the Royal Society of London, Series B: Biological Sciences 347, 205-212.

Gill, J. L., Williams, J. W., Jackson, S. T., Lininger, K. B. \& Robinson, G. S. (2009). Pleistocene megafaunal collapse, novel plant communities, and enhanced fire regimes in North America. Science 326, 1100-1103.

Gilljam, D., Thierry, A., Edwards, F. K., Figueroa, D., Ibbotson, A. T., Jones, J. I., Lauridsen, R. B., Petchey, O. L., Woodward, G. \& Ebenman, B. (2011). Seeing double: size-based and taxonomic views of food web structure. Advances in Ecological Research 45, 67-133.

Gillooly, J. F. \& Allen, A. P. (2007). Linking global patterns in biodiversity to evolutionary dynamics using metabolic theory. Ecology 88, 1890-1894.

Hartvig, M. \& Andersen, K. H. (2013). Coexistence of structured populations with size-based prey selection. Theoretical Population Biology 89, 24-33.

Hartvig, M., Andersen, K. H. \& Beyer, J. E. (2011). Food web framework for size-structured populations. Fournal of Theoretical Biology 272, 113-122.

Harvey, E., Séguin, A., Nozais, C., Archambault, P. \& Gravel, D. (2013). Identity effects dominate the impacts of multiple species extinctions on the functioning of complex food webs. Ecology 94, 169-179.

Heckmann, L., Drossel, B., Brose, U. \& Guill, C. (2012). Interactive effects of body-size structure and adaptive foraging on food-web stability. Ecology Letters 15, $243-250$.

Jochum, M., Schneider, F. D., Crowe, T. P., Brose, U. \& O'Gorman, E. J. (2012). Climate-induced changes in bottom-up and top-down processes independently alter a marine ecosystem. Philosophical Transactions of the Royal Society of London, Series B: Biological Sciences 367, 2962-2970.

Johnson, C. N. (2002). Determinants of loss of mammal species during the Late Quaternary 'megafauna' extinctions: life history and ecology, but not body size. Proceedings of the Royal Society of London Series B: Biological Sciences 269, 2221-2227.

Kalinkat, G., Schneider, F. D., Digel, C., Guill, C., Rall, B. C. \& Brose, U. (2013). Body masses, functional responses and predator-prey stability. Ecology Letters 16, $1126-1134$.

Kartascheff, B., Guill, C. \& Drossel, B. (2009). Positive complexity-stability relations in food web models without foraging adaptation. Fournal of Theoretical Biology $259,12-23$.

Kéfi, S., Berlow, E. L., Wieters, E. A., Joppa, L. N., Wood, S. A., Brose, U. \& Navarrete, S. A. (2015). Network structure beyond food webs: mapping non-trophic and trophic interactions on Chilean rocky shores. Ecology 96, 291-303.

Kéfi, S., Berlow, E. L., Wieters, E. A., Navarrete, S. A., Petchey, O. L., Wood, S. A., Boit, A., Joppa, L. N., Lafferty, K. D., Williams, R. J., Martinez, N. D., Menge, B. A., Blanchette, C. A., Iles, A. C. \& Brose, U. (2012). More than a meal... integrating non-feeding interactions into food webs. Ecology Letters 15, 291-300.

KLecKA, J. \& Boukal, D. S. (2013). Foraging and vulnerability traits modify predator-prey body mass allometry: freshwater macroinvertebrates as a case study. fournal of Animal Ecology 82, 1031-1041.

Lafferty, K. D., Allesina, S., Arim, M., Briggs, C. J., De Leo, G., Dobson, A. P., Dunne, J. A., Johnson, P. T. J., Kuris, A. M., Marcogliese, D. J., Martinez, N. D., Memmott, J., Marquet, P. A., Mclaughlin, J. P., Mordecai, E. A., Pascual, M., Poulin, R. \& Thieltges, D. W. (2008). Parasites in food webs: the ultimate missing links. Ecology Letters 11, 533-546.

Lafferty, K. D., Dobson, A. P. \& Kuris, A. M. (2006). Parasites dominate food web links. Proceedings of the National Academy of Sciences 103, 11211-11216.

Law, R., Plank, M. J., James, A. \& Blanchard, J. L. (2009). Size-spectra dynamics from stochastic predation and growth of individuals. Ecology 90, 802-811.

LEE, T. M. \& JETZ, W. (2011). Unravelling the structure of species extinction risk for predictive conservation science. Proceedings of the Royal Society of London Series B: Biological Sciences 278, 1329-1338.

van Leeuwen, A., de Roos, A. M. \& Persson, L. (2008). How cod shapes its world. Journal of Sea Research 60, 89-104.

Legagneux, P., Gauthier, G., Lecomte, N., Schmidt, N. M., Reid, D., Cadieux, M.-G., Berteaux, D., Bêty, J., Krebs, G. J., Ims, R. A., Yoccoz, N. G., Morrison, R. I. G., Leroux, S. J., Loreau, M. \& Gravel, D. (2014). Arctic ecosystem structure and functioning shaped by climate and herbivore body size. Nature Climate Change 4, 379-383.

Loreau, M. \& Hector, A. (2001). Partitioning selection and complementarity in biodiversity experiments. Nature 412, 72-76.

Martinez, N. D. (1991). Artifacts or attributes? Effects of resolution on the Little Rock Lake food web. Ecological Monographs 61, 367-392.

Martinez, N. D. (1992). Constant connectance in community food webs. The American Naturalist 139, 1208-1218.

MCCANn, K. S. (2000). The diversity-stability debate. Nature 405, 228-233.

McKie, B. G., Woodward, G., Hladyz, S., Nistorescu, M., Preda, E., Popescu, C., Giller, P. S. \& MalmQvist, B. (2008). Ecosystem functioning in stream assemblages from different regions: contrasting responses to variation in detritivore richness, evenness and density. Fournal of Animal Ecology 77, 495-504.

McKinney, M. L. (1997). Extinction vulnerability and selectivity: combining ecological and paleontological views. Annual Review of Ecology and Systematics 28, 495-516. 
Montoya, J. M., Pimm, S. L. \& Solé, R. V. (2006). Ecological networks and their fragility. Nature 442, 259-264.

Naisbit, R. E., Kehrli, P., Rohr, R. P. \& Bersier, L.-F. (2011). Phylogenetic signal in predator-prey body-size relationships. Ecology 92, 2183-2189.

Neutel, A.-M., Heesterbeek, J. A. P. \& De Ruiter, P. C. (2002). Stability in real food webs: weak links in long loops. Science 296, 1120-1123.

Olden, J. D., Hogan, Z. S. \& Vander Zanden, M. J. (2007). Small fish, big fish, red fish, blue fish: size-biased extinction risk of the world's freshwater and marine fishes. Global Ecology and Biogeography 16,694-701.

Otto, S., Rall, B. C. \& Brose, U. (2007). Allometric degree distributions stabilize food webs. Nature $450,1226-1229$.

Pereira, H. M., Leadley, P. W., Proença, V., Alkemade, R., Scharlemann, J. P. W., Fernandez-Manjarrés, J. F., Araujo, M. B., Balvanera, P., Biggs, R., Cheung, W. W. L., Chini, L., Cooper, H. D., Gilman, E. L., Guenette, S., Hurtt, G. C., et al. (2010). Scenarios for global biodiversity in the 21 st century. Science 330, 1496-1501.

Persson, L., Amundsen, P.-A., de Roos, A. M., Klemetsen, A., Knudsen, R. \& Primicerio, R. (2007). Culling prey promotes predator recovery-alternative states in a whole-lake experiment. Science 316, 1743-1746.

Petchey, O. L., Beckerman, A. P., Riede, J. O. \& Warren, P. H. (2008). Size, foraging, and food web structure. Proceedings of the National Academy of Sciences of the United States of America 105, 4191-4196.

Petchey, O. L., Beckerman, A. P., Riede, J. O. \& Warren, P. H. (2011). Fit, efficiency, and biology: some thoughts on judging food web models. Fournal of Theoretical Biology 279, 169-171.

Peters, R. H. (1983). The Ecological Implications of Body Size. Cambridge University Press, New York.

Pimm, S. L. (1982). Food Webs. Chapman \& Hall, New York

Pimm, S. L. \& Rice, J. C. (1987). The dynamics of multispecies, multi-life-stage models of aquatic food webs. Theoretical Population Biology 32, 303-325.

Plank, M. J. \& LAw, R. (2012). Ecological drivers of stability and instability in marine ecosystems. Theoretical Ecology 5, 465-480.

Poisot, T., Mouguet, N. \& Gravel, D. (2013). Trophic complementarity drives the biodiversity-ecosystem functioning relationship in food webs. Ecology Letters 16, 853-861.

Poulin, R. (2011). Evolutionary Ecology of Parasites. Second Edition 0. Princeton University Press, Princeton.

Purvis, A., Gittleman, J. L., Cowlishaw, G. \& Mace, G. M. (2000). Predicting extinction risk in declining species. Proceedings of the Royal Society of London Series B: Biological Sciences 267, 1947-1952.

Rall, B. C., Brose, U., Hartvig, M., Kalinkat, G., Schwarzmüller, F., Vucic-Pestic, O. \& Petchey, O. L. (2012). Universal temperature and body-mass scaling of feeding rates. Philosophical Transactions of the Royal Society of London, Series B: Biological Sciences 367, 2923-2934.

Reiss, J., Bridle, J. R., Montoya, J. M. \& Woodward, G. (2009). Emerging horizons in biodiversity and ecosystem functioning research. Trends in Ecology $\mathbb{E}^{\circ}$ Evolution 24, 505-514.

Reuman, D. C., Gislason, H., Barnes, C., Mélin, F. \& Jennings, S. (2014). The marine diversity spectrum. Fournal of Animal Ecology 83, 963-979.

Reuman, D. C., Mulder, G., Raffaelli, D. \& Cohen, J. E. (2008). Three allometric relations of population density to body mass: theoretical integration and empirical tests in 149 food webs. Ecology Letters 11, 1216-1228.

Riede, J. O., Binzer, A., Brose, U., de Castro, F., Curtsdotter, A., Rall, B. C. \& EkLöF, A. (2011a). Size-based food web characteristics govern the response to species extinctions. Basic and Applied Ecology 12, 581-589.

Riede, J. O., Brose, U., Ebenman, B., Jacob, U., Thompson, R., Townsend, C. R. \& Jonsson, T. (2011b). Stepping in Elton's footprints: a general scaling model for body masses and trophic levels across ecosystems. Ecology Letters 14, 169-178.

Riede, J. O., Rall, B. G., Banasek-Richter, C., Navarrete, S. A., Wieters, E. A., Emmerson, M. C., Jасов, U. \& Brose, U. (2010). Scaling of food-web properties with diversity and complexity across ecosystems. Advances in Ecological Research 42, 139-170.

Rohr, R. P., Scherer, H., Kehrli, P., Mazza, C. \& Bersier, L. (2010). Modeling food webs: exploring unexplained structure using latent traits. The American Naturalist 176, 170-177.

De Roos, A. M. \& Persson, L. (2001). Physiologically structured models - from versatile technique to ecological theory. Oikos 94, 51-71.

De Roos, A. M. \& Persson, L. (2013). Population and Community Ecology of Ontogenetic Development. Princeton University Press, Princeton.

Rudolf, V. H. W. \& LAfFerTy, K. D. (2011). Stage structure alters how complexity affects stability of ecological networks. Ecology Letters 14, 75-79.

Rudolf, V. H. W. \& Rasmussen, N. L. (2013). Population structure determines functional differences among species and ecosystem processes. Nature Communications 4, 2318.

Ruesink, J. L. \& Srivastava, D. S. (2001). Numerical and per capita responses to species loss: mechanisms maintaining ecosystem function in a community of stream insect detritivores. Oikos 93, 221-234.
De Ruiter, P. C., Neutel, A. M. \& Moore, J. C. (1995). Energetics, patterns of interaction strengths, and stability in real ecosystems. Science 269, 1257-1260.

de Ruiter, P. C., Wolters, V., Moore, J. C. \& Winemiller, K. O. (2005). Food web ecology: playing Jenga and beyond. Science 309, 68-71.

Rule, S., Brook, B. W., Haberle, S. G., Turney, G. S. M., Kershaw, A. P. \& Johnson, C. N. (2012). The aftermath of megafaunal extinction: ecosystem transformation in Pleistocene Australia. Science 335, 1483-1486.

Sallan, L. \& Galimberti, A. K. (2015). Body-size reduction in vertebrates following the end-Devonian mass extinction. Science 350, 812-815.

Schmid-Araya, J. M., Schmid, P. E., Robertson, A., Winterbottom, J., GJerløv, C. \& Hildrew, A. G. (2002). Connectance in stream food webs. Fournal of Animal Ecology 71, 1056-1062.

Schneider, F. D. \& Brose, U. (2013). Beyond diversity: how nested predator effects control ecosystem functions. Fournal of Animal Ecology 82, 64-71.

Schneider, F. D., Scheu, S. \& Brose, U. (2012). Body mass constraints on feeding rates determine the consequences of predator loss. Ecology Letters 15, 436-443.

Séguin, A., Harvey, É., Archambault, P., Nozais, C. \& Gravel, D. (2014). Body size as a predictor of species loss effect on ecosystem functioning. Scientific Reports 4 4616

Sheldon, R. W. \& Parsons, T. R. (1967). A continuous size spectrum for particulate matter in the sea. Fournal of the Fisheries Research Board of Canada 24, 909-915.

Solan, M., Cardinale, B. J., Downing, A. L., Engelhardt, K. A. M., Ruesink, J. L. \& SRivastava, D. S. (2004). Extinction and ecosystem function in the marine benthos. Science 306, 1177-1180.

Solé, R. V. \& Montoya, M. (2001). Complexity and fragility in ecological networks. Proceedings of the Royal Society of London Series B: Biological Sciences 268, 2039-2045.

Stouffer, D. B., Camacho, J. \& Amaral, L. A. N. (2006). A robust measure of food web intervality. Proceedings of the National Academy of Sciences of the United States of America 103, 19015-19020.

Stouffer, D. B., Rezende, E. L. \& Amaral, L. A. N. (2011). The role of body mass in diet contiguity and food-web structure. Foumal of Animal Ecology 80, 632-639.

Tamburello, N., Côté, I. M. \& Dulvy, N. K. (2015). Energy and the scaling of animal space use. The American Naturalist 186, 196-211.

TAng, S., Pawar, S. \& Allesina, S. (2014). Correlation between interaction strengths drives stability in large ecological networks. Ecology Letters 17, 1094-1100.

Thébault, E. \& Loreau, M. (2003). Food-web constraints on biodiversity-ecosystem functioning relationships. Proceedings of the National Academy of Sciences of the United States of America 100, 14949-14954.

Thierry, A., Beckerman, A. P., Warren, P. H., Williams, R. J., Cole, A. J. \& Petchey, O. L. (2011a). Adaptive foraging and the rewiring of size-structured food webs following extinctions. Basic and Applied Ecology 12, 562-570.

Thierry, A., Petchey, O. L., Beckerman, A. P., Warren, P. H. \& Williams, R. J. $(2011 b)$. The consequences of size dependent foraging for food web topology. Oikos 120, 493-502.

Thompson, R. M., Brose, U., Dunne, J. A., Hall, R. O. Jr., Hladyz, S., Kitching, R. L., Martinez, N. D., Rantala, H., Romanuk, T. N., Stouffer, D. B. \& TYlianakis, J. M. (2012). Food webs: reconciling the structure and function of biodiversity. Trends in Ecology \& Evolution 27, 689-697.

Tilman, D. (1999). The ecological consequences of changes in biodiversity: a search for general principles. Ecology 80, 1455-1474.

Wahlström, E., Persson, L., Diehl, S. \& Bystrom, P. (2000). Size-dependent foraging efficiency, cannibalism and zooplankton community structure. Oecologia 123, 138-148.

Walters, C. \& Kitchell, J. F. (2001). Cultivation/depensation effects on juvenile survival and recruitment: implications for the theory of fishing. Canadian fournal of Fisheries and Aquatic Sciences 58, 39-50.

Warren, P. H. \& LaWton, J. H. (1987). Invertebrate predator-prey body size relationships: an explanation for upper triangular food webs and patterns in food web structure? Oecologia 74, 231-235.

Warren, P. H., de Ruiter, P. C., Wolters, V. \& Moore, J. C. (2005). Wearing Elton's wellingtons: why body size still matters in food webs. In Dynamics Food Webs-Multispecies Assemblages, Ecosystem Development and Environmental Change (eds P. C. de Ruiter, V. Wolters and J. C. Moore), pp. 128-136. Academic Press Inc., San Diego.

Werner, E. E. \& Gilliam, J. F. (1984). The ontogenetic niche and species interactions in size-structured populations. Annual Review of Ecology and Systematics 15, 393-425.

White, E. P., Ernest, S. K. M., Kerkhoff, A. J. \& Enouist, B. J. (2007) Relationships between body size and abundance in ecology. Trends in Ecology \& Evolution 22, 323-330.

Williams, R. J., Anandanadesan, A. \& Purves, D. (2010). The probabilistic niche model reveals the niche structure and role of body size in a complex food web. PLoS One 5, e12092.

Williams, R. J. \& Martinez, N. D. (2000). Simple rules yield complex food webs. Nature 404, 180-183.

Woodward, G., Ebenman, B., Emmerson, M., Montoya, J. M., Olesen, J. M., VAlido, A. \& WARren, P. H. (2005). Body size in ecological networks. Trends in Ecology \& Evolution 20, 402-409.

Yodzis, P. (1981). The stability of real ecosystems. Nature 289, 674-676. 
Yvon-Durocher, G. \& Allen, A. P. (2012). Linking community size structure and ecosystem functioning using metabolic theory. Philosophical Transactions of the Royal Society of London, Series B: Biological Sciences 367, 2998-3007.

Yvon-Durocher, G., Montoya, J. M., Trimmer, M. \& Woodward, G. (2011a). Warming alters the size spectrum and shifts the distribution of biomass in freshwater ecosystems. Global Change Biology 17, 1681-1694.

Yvon-Durocher, G., Montoya, J. M., Woodward, G., Jones, J. I. \& Trimmer, M. $(2011 b)$. Warming increases the proportion of primary production emitted as methane from freshwater mesocosms. Global Change Biology 17, 1225-1234.
Yvon-Durocher, G., Reiss, J., Blanchard, J., Ebenman, B., Perkins, D. M., Reuman, D. C., Thierry, A., Woodward, G. \& Petchey, O. L. (2011c). Across ecosystem comparisons of size structure: methods, approaches and prospects. Oikos 120, 550-563.

Zhang, L., Thygesen, U. H., Knudsen, K. \& Andersen, K. H. (2013). Trait diversity promotes stability of community dynamics. Theoretical Ecology 6, 57-69.

Zook, A. E., Eklof, A., Jacob, U. \& Allesina, S. (2011). Food webs: ordering species according to body size yields high degree of intervality. Fournal of Theoretical Biology 271, 106-113.

(Received 24 October 2014; revised 3 December 2015; accepted 14 December 2015; published online 12 January 2016) 